\title{
THE INFLUENCE OF VENTILATION ON THE TYPE OF THE DISEASE.*
}

\author{
BY RICHARD PRICHARD, M.D., \\ Medical Officer of Health, Llandaff and Dinas Powis Rural District, President \\ of the West of England and South Wales Branch of the Society.
}

The physician has from very early times been trying to unravel the meaning, and to discover the cause, of the symptoms which he observed at the patient's bedside. It could not be expected that his primal inferences were always right because he was obliged to arrive at his conclusions unaided by a knowledge of physiology or pathology. But this first search for the vera causa of disease laid the foundation upon which the science of public health has been raised.

We know now that the touch of royalty is not as effectual in the cure of scrofula as good nourishment, cod-liver oil, and fresh seaair, coupled, if necessary, with the judicious use of the curette.

When the Arab doctors of old gave their patients powdered precious stones which they believed to be the abode of good spirits, they, like their successors of to-day, gave of their best for the relief of human suffering, and for the prevention of disease.

By reason of many of the healthy functions of animal life being periodical in their character-nay, many diseases are more prone to recur with the seasons-the old physicians from Paracelsus downwards argued that the heavenly bodies must exercise an influence on ours, and they sought for appropriate mineral and other remedies for each day of the week. While thus groping in the dark after the truth, we know that they made many valuable discoveries of which we now avail ourselves. They had no laboratories or instruments of precision such as we possess which enable us to penetrate in some instances behind the veil of the vital functions.

The great advance of bacteriology in recent years has led to the discovery of many germs which are specific to individual diseases. But there is probably too much tendency in our day to credit the micro-organism with being not only the exciting, but also the sole, cause of the disease. The elixir of life will be found when we have ascertained the exact conditions which are essential to the existence of the pathogenic organisms, and how to employ these conditions to our own advantage and protection. 
We find a notable instance of this in ague or intermittent fever. It is scarcely fifty years since this disease was very common in many localities in Wales, but as far as I know there is only one district where it may be contracted at the present time. The improvement in agriculture, necessitating the drainage of the stagnant pools and the marshes, has destroyed the breedingbeds of the (anophelæ) mosquito, thereby preventing its development beyond the larval stage. The more recent researches of Manson, Ross, and others, have demonstrated to us that the sting of this mosquito is essential in order to introduce the germ of malaria into the blood of man and so infect him.

It would appear in some instances that the amount of the specific infection which is introduced into the system may have something to do with the character of the attack which supervenes. Experiments on the lower animals lend colour to this view. Grancher's seemed to indicate that "Scrofula is a disease originating like ordinary tuberculosis, but due to a smaller dose of the virus" (Delépine). The truth probably lies in the fact that the scrofulous products are less virulent than those of ordinary tuberculosis. A few years ago a family in Cardiff had a keg of oysters sent them. All who partook of the oysters suffered from gastro-intestinal disturbanees. A girl, aged eleven years, who had been in weak health for some time beforehand, ate again of the succulent bivalve, and a fortnight later developed a typical attack of enteric fever. There was no doubt in my mind at the time that the oysters were the source of the infection, and the natural inference was that sh $\theta$ was the only one who had had a sufficient dose of it to excite an attack of typhoid fever. But the patient was previously weak in physique, and therefore predisposed to the disease-that is, less able to resist it. It is well known that the attack varies in severity at different periods during an epidemic. May it not be due to a varying dose of the virus which the patient has contracted? It is a moot question whether the dosage of the virus has any practical bearing on medicine and public health. When, however, we conconsider the character of the virus or infection, there are certain ascertained data which warrant us in deducing practical inferences. By the character of the virus I mean its pathogenicity or power of causing disease. Most of the known pathogenic micro-organisms can be modified by outside agencies, such as heat, light, or the medium on which they are grown. Take the familiar one of the vaccine of small-pox, which becomes modified by its passage through the horse or cow. It has still some of the attributes of small-pox in a minor degree. 
Pasteur long ago discovered that the small microbe which gave rise to "chicken cholera" was altered by its environments. When grown in laboratory "broth" which was kept in a sterile flask plugged with cotton-wool, so as to allow only the oxygen of the air to enter, it changed its character. That which was during the first week or so highly pathogenic gradually lost its virulence, so that in course of two months or so it would not kill a single fowl, and apparently caused them no inconvenience. This attenuation of virulence was produced by the air alone. The same microbe kept in a sealed tube into which no air could enter would soon cease to grow, but its virulence would remain unimpaired for a year or longer. The bacillus of anthrax, and of several others, may be modified in a like manner. M. Roux duly reminds us of the equally important fact that "it is also possible to make the bacillus reascend the steps of virulence down which it has come, and so to render it once more virulent." Do these vital processes take place in the laboratory of Nature? Is the periodicity of epidemics solely dependent on the existence of fresh supply of susceptible subjects -that is, persons who are not protected by a previous attack of the same fever? It has been demonstrated that sunlight and oxygen of the air exert a powerful attenuating influence on many of the specific germs, thus acting as Nature's disinfectants. Allusion has already been made to the patient being possibly predisposed on the ground of health to disease, and I now propose to refer shortly to the converse quality-viz., the power to resist attack. It is the physician's daily experience to see patients stricken with disease whilst other members of the same family escape. The latter are, for the time being at least, proof against the infection. Again, hardly any two members of the same household suffer in an equal degree. Typhoid fever is often so atypical in young children as to be hardly recognisable as such; yet individuals grow less susceptible to the disease as they advance in years. The laboratory furnishes many interesting examples of this variation in vulnerability. The bacillus of mouse septicæmia, whick is rapidly fatal to housemice, is harmless to field-mice. Cows, goats, and most breeds of sheep, are, if inoculated, very susceptible to anthrax; but the Algerian sheep is immune. (The field-mouse and the Algerian sheep live always in the open air.) The rat is also highly resistant to anthrax, but if fed for a time on bread or vegetarian diet it loses its former immunity.

The rabbit appears to be immune against the virus of "quarter evil " even if the virus is injected into the thigh, but if it should happen that the thigh has been bruised or injured in any way the 
microbe may start to grow and ultimately kill the animal. We observe a somewhat similar instance in the human being. The Staphylococcus pyogenes albus is normally present in myriads on the skin and even in healthy wounds. But should the tension in the wound be excessive, the resistance of the tissue is diminished, and the otherwise innocent micro-organism may then excite what is called "stitch abscess." Curtis remarks that "damaged tissue may be looked upon as an area to a greater or less extent deprived of its normal protective mechanism." What constitutes this resistance? I have no intention of referring to the absorbing question of immunity, beyond stating that it is my strong conviction that we can do much to strengthen the phagocytes, or "defensive proteids," so that the system may be able to resist infection, or at least to such an extent as to prevent a severe or malignant attack. The conditions which produce malignancy are identical with those which conduce to an attack of the disease. In making this statement I am reminded of what Aug. Gottlieb Richter said more than a hundred years ago: "In no science does selfsufficiency or bold and general assertion and decided axioms more certainly mark ignorance and want of experience than in the science of medicine." I am not stating my own opinion entirely. It has been conclusively established by Dr. Marie Raskin and others that the cause of those complications which give rise to malignant attacks of scarlet fever, diphtheria, etc.--such as lymphadenitis, abseess, otitis, purulent synovitis, broncho-pneumonia, pleurisy, pyæmia, and septicæmia-is secondary infection of Streptococcus pyogenes. The same micro-organism is reputed to be the cause of hectic fever in phthisis. And yet it may be found quite harmless in the mouth of a perfectly healthy individual. The streptococci, less often staphylococci, give rise to the early severe symptoms in diphtheria. As Dr. Savage observes: "When the diphtheria bacillus is found in pure culture in the throat the attack is usually of a mild type."

Since we have been in the habit of verifying our diagnosis of diphtheria by taking a swab of the patient's throat for bacteriological examination, I am doubtful if we should regard the presence of membrane in the throat as pathognomonic of true diphtheria. Dr. Savage has repeatedly found the Löffer's bacillus in almost pure culture where there was little or no evidence of the characteristic membrane. On the other hand, where there has been a typical and well-marked membrane only cocci could usually be detected. So far this has always been the result in the few cases of membranous sore throat complicating scarlet] fever which $I$ have met 
with and that were bacteriologically investigated. The Löffler's bacillus has often been found in the throat and air-passages of persons who have been in contact with patients suffering from diphtheria. For some cause the disease did not develop at all, or not till after a prolonged interval. I have been consulted within the last few months by a boy and a girl who were suffering from post.diphtheritic paralysis following mild attacks of "sore throat." They were the cause of extensive and fatal outbreaks of diphtheria in their several localities. There is, to my mind, very strong circumstantial evidence that the main instruments in the causation of the severe or malignant type of infectious diseases we meet with are the "pus" cocci to which I have referred. Indeed, I have found, almost without exception, that the patients admitted to the isolation hospital with the above type of scarlet fever had cardiac bruit and other symptoms of septic absorption. This was so in one or two instances even as early as the second day of the attack, indicating a grave state of health probably anterior to the scarlatina.* What is the cause of it? About fifteen years ago a country practitioner invited me to see a lad, eight years old, who had malignant scarlet fever, from which he died two days later. Another child, two years old, had died the day before that from symptoms of acute poisoning, but which were doubtless those of searlet fever. The home was a small thatched cottage, in a dry, healthy situation, and the surroundings were quite sanitary. The family sleepingroom was miserably small, hardly sufficient for one person, and the solitary little window was not made to open. The air of the room was unbearably foul. I was profoundly impressed with the situation, and I could not help asking myself the question: Was it the want of fresh air that was the cause of the many malignant cases which I had seen during my residence at the Glasgow fever hospitals? Subsequent observations, both in my public and in my private work, have convinced me that in nearly every instance the mild attacks are in patients who have been accustomed to live and sleep in airy rooms, and the malignant types are the products of defective ventilation. About this time twelvemonth a young girl was brought to hospital from a cottage on Leckwith Hill. It was

* Since writing the above, I have read the following statement in the Medical Officer to the Local Government Board's Report for 1900-1901: "Dr. Mervyn Gordon, who has for some years been carrying on experiments on the intimate pathology of scarlatina, infers that the graver manifestations of scarlatina are due, not to a single but to a twofold ageney; that the infectious malady, searlatina, is to be referred to Streptococeus scarlatina, whereas the dangerous phases of the disease, and especially its fatal tendeney, frequently result from supplementary invasion of the blood and tissues of the patient by Streptococous pyogenes." 
the third day of illness; she had scarlatina anginosa, immature petechial rash, and endocarditis. I remarked to the matron, "This child has been sleeping in impure air." Two days later the brother was admitted. The nurse who went with the ambulance said, on her return, "The air in the room was frightfully bad; it nearly made me sick. I took up the boy and rushed out with him." I need not say that this boy had an attack similar to his sister. I could adduce numerous instances illustrating conditions like these which seemed to regulate and govern the character of the attack in typhoid fever and other diseases. Quite recently I came across the following paragraph in Dr. Ballard's classical report on the Etiology of Diarrhoea: "The absence of free domestic ventilation increases very greatly and very obviously the mortality from diarrhoa, and this very much more than it increases the mortality from all causes put together; more, indeed, than it does the mortality from the seven principal "zymotics" put together, and very much more than it affects the mortality from all causes except the seven "zymotics."

In Parkes' "Manual of Practical Hygiene" attention is directed to the influence of bad air on pneumonia. "In the South Afghanistan field force the artillery wintered at Candahar (1880-1881) in tents, and remained free from pneumonia, whilst the disease was prevalent among the infantry who were overcrowded in barracks. The 63rd Regiment, which was more crowded than the other corps, suffered most, having thirty cases in hospital at one time; one company, however, quartered in large airy rooms near the residence of the General commanding, had no case. On March 25th a part of the regiment was turned out into tents, and the remainder were distributed in barracks, so that each man had a minimum of 600 cubic feet of space; from that time no more pneumonia occurred."

It is not necessary for me to remind you of that with which you are perfectly familiar from your observations apart from your studies-that phthisis, above all, is a disease of bad ventilation. The barracks, the navy, and the prisons in the old days were hotbeds of consumption, but with more ample accommodation and purer air-whilst other conditions such as food, exercise, etc., remain much the same-the death-rate from phthisis is considerably less amongst these servants and prisoners of the State than amongst the civil population (L. Parkes). If we are to combat tuberculosis successfully we must, by means of fresh air, prevent, if possible, the pathogenic action of the micro-organisms which excite inflammatory processes in the tissues. There is every indication, 
as Klebs, Biedert, and Ziegel have maintained, that "bacillary invasion must be preceded by some preparatory lesion." The tubercle bacillus is not a very aggressive germ primarily; it grows where the soil has been prepared for it, or, as in the instance of the virus of "quarter evil" in the rabbit, where the resistance of the tissues has been previously undermined.

Those of us who have had to do with isolation hospitals must have noticed repeatedly that whenever we have crowded our wards complications become increasingly frequent.

The public elementary schools are, I fear, not infrequently a source of mischief in this respect. If the young ehild who sleeps in a badly ventilated room attends a school where the too limited cubic space required by law is further encroached upon by the average attendance being in excess of the accommodation, its health must get undermined. Still worse is "the lot of those children who, for the sake of respectability, are "educated" in the small so-called private schools. There is no fault to find with those which have specially built schoolrooms, but I allude to those which are held in ordinary dwelling-rooms of a small house. They are frequently so excessively overcrowded as to be more than a danger to health. I have often heard parents remark that their children take ill as soon as they return to such school. They suffer from loss of appetite, anæmia, and recurring attacks of catarrh of the air-passages, and they are predisposed thereby to more serious troubles. I think that we medical officers of health should take every active measure we can to suppress this very prevalent, grave nuisance.

What is, then, this materies morbi in badly ventilated rooms occupied by human beings or other animal life? I will answer that question by relating some experiments which had reference to expired air. Ben and Rauer arranged a series of air-tight glass chambers, in each of which a mouse was placed. The chambers were connected with each other, so that the second mouse breathed the expired air of the first and the third of both, and so on. The air was drawn through the apparatus by means of a pump. It was found that the last animal died first, then the next. Rauer thought that death must have been due to carbon dioxide. Merkel carried the experiment a stage further to prove if it was so, or if it was due to an organic body. He placed a tube containing 1 per cent. sulphuric or hydrochloric acid between the third and fourth chambers. The acid would absorb any organic matter, but would allow the carbonic acid to pass on. In this instance the third mouse died first, the fourth remaining all right, showing that the $\mathrm{CO}_{2}$ was not the cause 
of death. Similar experiments were made years ago by the late Brown-Séquard and M. D'Arsonval on rabbits and guinea-pigs, taking care to remove any excreta and débris of food. The animals died from a day to several months, according to the concentration of the impurities. The interposition of sulphuric acid to absorb organic matter prevented fatal results even though the carbon dioxide amounted to 4 or 6 per cent. Brown-Séquard stated in 1887 that guinea-pigs inoculated with tubercle eseaped the disease if kept day and night in the open air, whereas they nearly always died if kept in the laboratory, where the ventilation was imperfect. Some very interesting analyses were made at Dundee by Haldane and others of the air of sleeping-rooms after they had been occupied for some hours. The number of microbes per litre varied from eighty in a room of from 100 to 180 eubic feet per head to only six per litre in a room having a capacity of from 500 to 1,000 cubic feet. Curiously enough, the number of microbes increased with larger sized rooms, showing that above a certain size of room the air does not circulate so freely, or is more conducive to the growth of microorganisms. They evidently grow readily in the moist organic matter exhaled by the lungs.

I am desirous of not labouring this question of the importance of fresh air; I submit that I have adduced some evidence to prove that " the conditions which produce malignaney are identical with those which conduce to an attack of the disease," viz., overcrowding and consequent bad ventilation. The bearing of foul air on the causation of consumption is now being gradually recognised by the public, but the remedy is so cheap and so simple that, like Naaman of old, they will go on asking for some greater thing to be done.

In a young country like Canada, which loses from 7,000 to 8,000 of its population annually from tuberculosis, the prevention of consumption naturally assumes great political importance. The difficulty of ventilating the houses there during the winter weather must be considerable. Tuberculosis is, I am told, increasing among the herds, causing serious losses to the farmers. I recently had a conversation with a gentleman from Canada who takes great personal interest in this subject, and I asked him how the cattle were housed during the winter; he replied that "The buildings are usually under the barns for the sake of warmth." These, then, are exactly the conditions which make infection possible under the most favourable circumstances.

How is this state of things to be remedied? Sanitary authorities have considerable power, if they use it, and their officers are active and intelligent, to render the houses and their surroundings 
healthful; but the "sanitaryman" is often regarded with a good deal of prejudice, as if he had some personal end to serve. $\mathrm{He}$ cannot insure the ventilation of sleeping-rooms at night.

It should be a subject of instruction in the elementary and other schools. Some of the seed would doubtless fall on good ground and bring forth fruit in years to come. But it would not affect the urgent present needs.

The patient usually relies upon the advice of the physician in matters of health, and, though not always, carries out his instructions. I may be mistaken, but I think that a very great deal more may be done by the personal teachings of the family doctor than by any other means, and I therefore exhort the medical profession generally to take every opportunity to preach the gospel of sweetness and light.

The Provision of Sanatoria. - With regard to the provision of sanatoria, a word of warning seems necessary at present. Influenced to some extent by a prevailing fashion, the Congress on Tuberculosis passed a resolution that the provision of sanatoria is an "indispensable" part of the measures to be taken against tuberculosis. This is a rather strong statement of the case, in view of what we know as to the steady reduction in the death-rate from phthisis which has taken place under general sanitary measures. And any attempt to deal with tuberculosis along the same lines as those adopted for the common infectious diseases, such as small-pox and scarlet fever, by the segregation of cases must inevitably prove impracticable, and, supposing that it were practicable, would be an unnecessary and very costly method of dealing with the matter. It may safely be said that a given sum of money invested under the provisions of the Housing of the Working Classes Act will do more towards the permanent reduction of the death-rate from phthisis than many times the same sum expended on the building and support of sanatoria. Under the existing state of things, sanatoria for phthisis must be regarded mainly as institutions for dealing with the results of tuberculosis, and the provision of them should not be classed as amongst those larger "indispensable" measures which have to be taken by sanitary authorities for the prevention of the disease. Of the usefulness of sanatoria in the treatment of phthisis there can be no question, and their provision by private benevolence for the treatment and assistance of individuals of the poorer class of phthisical patients, and by Boards of Guardians for the treatment of paupers, cannot be too strongly urged. But to suppose that the isolation for a few months of a few of the large number of patients who in this country are suffering from phthisis will have an effect on the prevalence of the disease which will be in any degree commensurate with the cost, or will approach in usefulness the result which would be obtained by the expenditure of the same amount of money in other directions, is a supposition which is probably founded on several fallacies.-A. G. R. Foulerton, Annual Report of the East Sussex County Council. 